\title{
Fourteen-year trends in sodium content of menu offerings at eight leading fast-food restaurants in the USA
}

\author{
Amanda Rudelt, Simone French and Lisa Harnack* \\ Division of Epidemiology and Community Health, School of Public Health, University of Minnesota, 1300 South \\ $2^{\text {nd }}$ Street, Minneapolis, MN 55454, USA
}

Submitted 22 October 2012: Final revision received 17 June 2013: Accepted 25 July 2013: First published online 10 September 2013

\begin{abstract}
Objective: To examine changes in the Na content of lunch/dinner menu offerings at eight of the leading fast-food restaurants in the USA between 1997/1998 and 2009/2010.

Design: Menu offerings and nutrient composition information for the menu items were obtained from archival versions of the University of Minnesota Nutrition Coordinating Center (NCC) Food and Nutrient Database. Nutrient composition information for lunch/dinner menu items sold by the fast-food restaurants included in the present study was updated in the database biannually. Menus were analysed for changes in mean $\mathrm{Na}$ content of all menu offerings (except beverages) and specific categories of menu items among all restaurants and for each individual restaurant.

Setting: USA.

Subjects: Lunch/dinner food menu of eight leading US fast-food restaurants.

Results: Between 1997/1998 and 2009/2010 the mean Na content of menu offerings across the eight restaurants increased by $23.4 \%$. Examining specific food categories, mean $\mathrm{Na}$ content of entrées by increased $17 \cdot 2 \%$ and that of condiments increased by $26 \cdot 1 \%$. Only side dishes showed a decrease of $6 \cdot 6 \%$. None of the restaurants examined had a decrease in $\mathrm{Na}$ across the lunch/dinner menu offerings over the 14 years examined.

Conclusions: Results suggest that over the time period studied there has been no meaningful reduction in the Na content of lunch/dinner menu offerings at the leading fast-food restaurants examined in the present study.
\end{abstract}

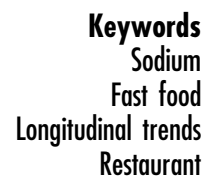

In the USA high dietary $\mathrm{Na}$ intake is associated with more attributable deaths than any other single dietary risk factor ${ }^{(1)}$. It is well known that excess dietary Na raises blood pressure, and this effect has been documented in both adults ${ }^{(2)}$ and children ${ }^{(3)}$. High blood pressure is the most common risk factor for heart disease and stroke, the first and fourth leading causes of death in the USA. High-Na diets are also associated with kidney disease and osteoporosis ${ }^{(4)}$, as well as stomach cancer $^{(5)}$.

Virtually all Americans consume more $\mathrm{Na}$ than recommended. Current dietary guidelines recommend a maximum daily intake of no more than $2300 \mathrm{mg} \mathrm{Na}$ and recommend an even further reduction to $1500 \mathrm{mg} \mathrm{Na} / \mathrm{d}$ for children, people 51 years of age or older, and those of any age who are African American, or currently have hypertension, diabetes or chronic kidney disease ${ }^{(6)}$. The $1500 \mathrm{mg}$ recommendation applies to more than half the US population $^{(7)}$, but currently less than $15 \%$ of Americans consume less than $2300 \mathrm{mg} \mathrm{Na} / \mathrm{d}^{(8)}$. Less than $1 \%$ of Americans adults are meeting the $1500 \mathrm{mg} / \mathrm{d} \mathrm{goal}^{(8)}$.
Restaurant food as a whole is among the major contributors to $\mathrm{Na}$ in the American diet, with national dietary survey data indicating that one-quarter of all $\mathrm{Na}$ consumed by Americans is from this source. The subset of fast-food and pizza restaurants alone accounts for 13.6\% of total $\mathrm{Na}$ intake ${ }^{(9)}$. While African Americans have a lower recommended upper $\mathrm{Na}$ limit there is often a higher concentration of fast-food chains in America's lower-income and urban black neighbourhoods ${ }^{(10)}$.

Restaurant food is a major source of $\mathrm{Na}$ due to how frequently Americans eat out and the high $\mathrm{Na}$ content of foods available at restaurants. In 2002, $50 \%$ of US food dollars were spent on foods eaten away from home ${ }^{(11)}$. Fast food is the leading source of food eaten away from home in the USA, accounting for about $38 \%$ of spending on food eaten away from home ${ }^{(12)}$. A recent survey of adults found that $80 \%$ purchased fast food in the last month and $28 \%$ consumed fast food two or more times per week $^{(13)}$. Fast-food restaurant meals have been found to be high in $\mathrm{Na}^{(14)}$. In addition, frequent fast-food consumption has been associated with higher $\mathrm{Na}$ intake ${ }^{(15)}$. 
In consideration of the significant contribution of restaurant foods to $\mathrm{Na}$ in the American diet, the industry has been encouraged to lower the Na content of its menu offerings $^{(7,16,17)}$. In 2010, with support of the Centers for Disease Control and Prevention, the New York City Department of Health and Mental Hygiene created the National Sodium Reduction Initiative, a public-private partnership to set $\mathrm{Na}$ reduction goals and track progress across food categories. Target dates to meet Na reduction goals were set for 2012 and 2014. Currently only twentyeight food manufacturers including five restaurant chains have agreed to participate in meeting $\mathrm{Na}$ reduction goals in any of the sixty-eight food categories. To date, just two unpublished studies have examined trends in the $\mathrm{Na}$ content of restaurant menu offerings and only a small number of products were examined ${ }^{(18,19)}$. Thus, we have conducted a study to examine the change in the $\mathrm{Na}$ content of menu item offerings at eight leading fast-food restaurants in the USA over the past 14 years. More specifically, we examined whether the $\mathrm{Na}$ content of menu offerings at eight of the leading fast-food restaurants changed between 1997 and 2010, and if there were differences between specific fast-food restaurant chains in the pattern of change in $\mathrm{Na}$ content of the menu items over this time period. To our knowledge, this is the first comprehensive study to quantitatively examine changes in the $\mathrm{Na}$ content of fast-food menu offerings over time.

\section{Experimental methods}

Current and archival versions of the University of Minnesota Nutrition Coordinating Center (NCC) Food and Nutrition Database were utilized to examine trends in the $\mathrm{Na}$ composition of leading fast-food restaurant menus. Currently, this database includes menu items available at twenty-two US fast-food restaurant chains. Fast-food restaurants are selected for inclusion in this database on the basis of both popularity and availability of company-provided product ingredient listings and nutrient composition information for standard menu items. Therefore, most - but not all - leading fast-food restaurants are included in the database.
Of the twenty-two restaurants currently in the NCC Food and Nutrient Database, eight were selected for inclusion in the present study, reflecting $49 \cdot 8 \%$ of the total sales of the top fifty US fast-food restaurants in $2009^{(20)}$. Restaurants were included in the study if the restaurant had been included in the database since 1997, the restaurant had a defined set of menu offerings and all standard menu offerings were included in the database.

The eight restaurants included in the present study are among the leading restaurants in the USA with regard to annual sales and number of locations (Table 1). The menu items available at each of the selected restaurants and their nutrient composition were updated in the database every other year on an alternating schedule over the time period included in the present analysis, thus allowing for examination of marketplace trends over an extended period of time. To maintain a steady workload in updating the database annually, restaurants were slotted into one of two update rounds in roughly equal numbers (e.g. about one-half of restaurants were slotted into one round and the other one-half into the other round). Updates were done on a rotating basis such that restaurants in each round were updated once every two years. Due to the alternating nature of the updates, trends were examined in seven 2-year time periods (1997/1998, 1999/2000, 2001/2002, 2003/2004, 2005/2006, 2007/2008 and 2009/2010) ensuring that all restaurants are represented in each period.

\section{NCC Food and Nutrient Database}

The NCC Food and Nutrient Database is maintained using a standard set of well-defined and described procedures $^{(21-24)}$. When updating nutrient information for a restaurant, a listing of all foods and beverages on the restaurant's breakfast and lunch/dinner menu is obtained from the restaurant corporation's website or publications produced by the company such as brochures or posters. The product nutrient composition and ingredient information is also obtained from these sources and used to create a formulation using an NCC-developed linear optimization algorithm that estimates the amount of each ingredient needed to produce a product with the given

Table 1 Annual US sales ranking and database update schedule between 1997 and 2010 for each fast-food restaurant included in the study analysis ${ }^{(20)}$

\begin{tabular}{lcccc}
\hline Restaurant & 2010 ranking & $\begin{array}{c}2009 \text { annual sales } \\
\text { (\$US millions) }\end{array}$ & Market share* $(\%)$ & Database update schedule \\
\hline McDonald's & 1 & $31000 \cdot 0$ & $22 \cdot 4$ & $1998,2000,2002,2004,2006,2008,2010$ \\
Burger King & 3 & $9000 \cdot 0$ & $6 \cdot 5$ & $1997,1999,2001,2003,2005,2007,2009$ \\
Wendy's & 4 & $8388 \cdot 0$ & $6 \cdot 1$ & $1998,2000,2002,2004,2006,2008,2010$ \\
Taco Bell & 6 & $6800 \cdot 0$ & $4 \cdot 9$ & $1998,2000,2002,2004,2006,2008,2010$ \\
KFC & 9 & $4900 \cdot 0$ & $3 \cdot 5$ & $1997,1999,2001,2003,2005,2007,2009$ \\
Arby's & 11 & $3228 \cdot 8$ & $2 \cdot 3$ & $1997,1999,2001,2003,2005,2007,2009$ \\
Jack in the Box & 13 & $3072 \cdot 1$ & $2 \cdot 2$ & $1998,2000,2002,2004,2006,2008,2010$ \\
Dairy Queen & 16 & $2640 \cdot 0$ & $1 \cdot 9$ & $1997,1999,2001,2003,2005,2007,2009$ \\
\hline
\end{tabular}

*Percentage of total sales of the top fifty US fast-food/quick-serve restaurants (restaurants without a wait-staff) in 2009. 
nutrient profile. From this formulation more detailed nutrient composition can be calculated.

A number of conventions are followed by NCC in maintaining fast-food restaurants in the database. As a rule, all portion sizes available for food items on restaurant menus are included in the database (e.g. small, medium, large French fries are included in the database). Exceptions to this rule include chicken entrée items such as chicken nuggets and strips which are included in the database in the unit of 'piece' or 'each' rather than by order size. With respect to foods that may be ordered with various topping options, entries are generally included in the database for the food and each topping separately. For example, salads at restaurants may generally be ordered with a choice of dressing. Therefore, the salad and each dressing choice are included as separate items in the database. Seasonal and short-term promotional menu items are generally not included in the database.

\section{Creation of data set for trends analysis}

For the present analysis a data set was created that included all menu items available at the eight restaurants during each time point. Although breakfast menu items were included in this data set, for the present study only lunch/dinner menu items were included in the analyses because not all of the restaurants offered breakfast over the study period. Menu items classified as drinks were also excluded from the analysis because beverages are generally not considered to be a significant source of $\mathrm{Na}$. In the data set each available serving size of a food was included as a unique menu item. Therefore, changes in portion size over time, such as the addition or removal of an extra large or an extra small sized French fries order, and the accompanying changes in $\mathrm{Na}$ content of the item, would be detected. Condiments and toppings that were available as additional options to foods (e.g. salad dressing packet choices, sauce packets for chicken items, etc.) were included as separate menu items in the data set.

In order to evaluate changes in the $\mathrm{Na}$ content of menu items in specific categories and sub-categories of food over time, menu item categories were established (e.g. entrées, side dishes, etc.) and classification criteria were developed after review of the range of foods offered by each restaurant each year.

\section{Statistical analysis}

To assess overall change over the 14 years of data across all eight restaurants, descriptive statistics including the number of items on the menu and the mean, median, range and interquartile range of $\mathrm{Na}(\mathrm{mg})$ were calculated for all menu items, as well as categories of entrées, side items and condiments. To evaluate restaurant-specific changes in the $\mathrm{Na}$ content of food offerings between 1997/1998 and 2009/2010, the mean Na for each restaurant was reported for each time period and the percentage change in mean $\mathrm{Na}(\mathrm{mg}) / \mathrm{menu}$ item was calculated between these two time periods. Because the menu items included in the analysis represent the entire population of foods offered at each restaurant, and the restaurants were not selected randomly in an effort to be representative of all fast-food restaurants, statistical testing and related $P$ values are not appropriate. All analyses were completed using the statistical software package Stata SE 11·2.

\section{Results}

\section{Trends in number of menu items offered}

During the 14-year period the number of non-beverage lunch/dinner food item offerings across the selected eight fast-food restaurant increased from 450 menu items to 695 menu items (Table 2). Within each of the food subcategories examined the number of offerings increased.

\section{Trends in Na content of menu offerings}

Across the eight restaurants mean $\mathrm{Na}$ content of menu offerings increased by $23 \cdot 4 \%$ over the 14 years studied (Table 2). The mean Na content of entrées increased by $17 \cdot 2 \%$, from $934 \mathrm{mg} \mathrm{Na} /$ item to $1095 \mathrm{mg} \mathrm{Na} /$ item. The mean Na content of side dishes decreased by $6.6 \%$, from $624 \mathrm{mg} \mathrm{Na}$ /item to $583 \mathrm{mg} \mathrm{Na}$ /item. Side dishes, which included fruit offerings and side salads, was the only sub-category of food that showed a reduction in $\mathrm{Na}$. It should be noted that salad dressings and fruit dipping sauces were included in the condiment sub-category which showed a $26 \cdot 1 \%$ increase in mean $\mathrm{Na}$, from $249 \mathrm{mg}$ $\mathrm{Na} /$ item to $314 \mathrm{mg} \mathrm{Na}$ /item.

Mean Na increased markedly between 2003/2004 and 2005/2006, from $649 \mathrm{mg} \mathrm{Na/item} \mathrm{to} 752 \mathrm{mg} \mathrm{Na} /$ item, respectively. There also was a slight decrease in mean $\mathrm{Na}$ between 2005/2006 and 2007/2008, from $752 \mathrm{mg} \mathrm{Na/item}$ to $735 \mathrm{mg} \mathrm{Na}$ /item. A marked increase in the upper end of the range was also evident in 2005/2006. The maximum Na content of menu item offerings varied from a low of $2515 \mathrm{mg}$ in $1997 / 1998$ to a high of $4642 \mathrm{mg}$ in the $2005 / 2006$ reporting period. Further examination of the outliers determined that two separate chicken sandwiches were offered in the 2005/2006 reporting period that had over $4500 \mathrm{mg} \mathrm{Na}$ each. These sandwiches contained almost $1500 \mathrm{mg}$ more Na than the next highest menu offering over any reporting period. Removing these two offerings from the analysis brought the mean from the 2005/2006 reporting period to $739 \mathrm{mg} \mathrm{Na}$ /item (from $752 \mathrm{mg} \mathrm{Na} /$ item). Thus, removing these items from the analysis does not completely explain the sharp increase in mean Na between 2003/2004 and $2005 / 2006$. However it does show that there was no notable difference in the average $\mathrm{Na}$ content of menu offerings between 2005/2006 and 2007/2008 when these two sandwiches were excluded from the analysis. This indicates that the downward trend in mean $\mathrm{Na}$ observed between these time periods may be attributable to the removal of these items from menu offerings in 2005/2006. 
Table 2 Trends in sodium content of menu offerings at eight leading US fast-food restaurants between 1997/1998 and 2009/2010

\begin{tabular}{|c|c|c|c|c|c|c|c|c|}
\hline & & $1997 / 1998$ & $1999 / 2000$ & $2001 / 2002$ & $2003 / 2004$ & $2005 / 2006$ & $2007 / 2008$ & $2009 / 2010$ \\
\hline \multirow[t]{6}{*}{ Complete lunch/dinner food menu } & $\begin{array}{l}\text { No. of items } \\
\mathrm{mg} \mathrm{Na} / \text { item }\end{array}$ & 450 & 457 & 472 & 509 & 574 & 590 & 695 \\
\hline & Mean & 624 & 632 & 643 & 649 & 752 & 735 & 770 \\
\hline & SD & 498 & 523 & 522 & 523 & 608 & 552 & 583 \\
\hline & Median & 525 & 525 & 546 & 549 & 647 & 679 & 691 \\
\hline & IQR & $111-946$ & $199-926$ & 209-912 & $198-942$ & $253-1106$ & $250-1100$ & $277-1133$ \\
\hline & Range & $0-2515$ & 0-3012 & $0-2616$ & $0-2436$ & $0-4642$ & $0-2984$ & $0-3150$ \\
\hline \multirow[t]{6}{*}{ Lunch/dinner entrée } & $\begin{array}{l}\text { No. of items } \\
\mathrm{mg} \mathrm{Na} \text { /item }\end{array}$ & 211 & 212 & 221 & 230 & 297 & 315 & 380 \\
\hline & Mean & 934 & 950 & 969 & 1013 & 1125 & 1070 & 1095 \\
\hline & SD & 469 & 514 & 497 & 496 & 582 & 493 & 518 \\
\hline & Median & 883 & 878 & 875 & 928 & 1062 & 1022 & 1015 \\
\hline & IQR & $615-1189$ & $617-1189$ & $622-1238$ & $654-1320$ & $710-1426$ & $740-1400$ & $729-1419$ \\
\hline & Range & $24-2515$ & $41-3012$ & $50-2616$ & $98-2436$ & $27-4642$ & $29-2984$ & $76-3150$ \\
\hline \multirow[t]{6}{*}{ Side dishes } & $\begin{array}{l}\text { No. of items } \\
\mathrm{mg} \mathrm{Na} \text { /item }\end{array}$ & 71 & 72 & 77 & 78 & 94 & 93 & 105 \\
\hline & Mean & 624 & 633 & 608 & 549 & 483 & 507 & 583 \\
\hline & SD & 427 & 449 & 461 & 420 & 374 & 422 & 542 \\
\hline & Median & 636 & 633 & 537 & 457 & 437 & 378 & 495 \\
\hline & IQR & $205-933$ & $222-879$ & $245-803$ & $196-870$ & $158-782$ & $158-797$ & 198-802 \\
\hline & Range & $0-1743$ & $0-1743$ & $0-2601$ & $0-1640$ & $0-1468$ & $0-1800$ & $0-2629$ \\
\hline \multirow[t]{6}{*}{ Condiments } & $\begin{array}{l}\text { No. of items } \\
\mathrm{mg} \mathrm{Na} \text { /item }\end{array}$ & 74 & 78 & 76 & 92 & 96 & 96 & 108 \\
\hline & Mean & 249 & 262 & 268 & 314 & 343 & 317 & 314 \\
\hline & $\mathrm{SD}$ & 221 & 223 & 227 & 260 & 288 & 245 & 223 \\
\hline & Median & 163 & 212 & 231 & 221 & 259 & 259 & 263 \\
\hline & IQR & $86-386$ & $95-413$ & $87-388$ & $101-494$ & $134-559$ & $138-418$ & $145-425$ \\
\hline & Range & $1-1010$ & $0-1022$ & $1-1028$ & $1-1080$ & $1-1599$ & $1-1060$ & $1-901$ \\
\hline
\end{tabular}

IQR, interquartile range.

\section{Trends in restaurant-specific menu offerings}

None of the restaurants examined had a decrease in mean $\mathrm{Na}$ across the lunch/dinner menu over the 14 years of observation. Rather, increases ranging from $6 \%$ to $55 \%$ were seen at seven of the eight restaurants and no change occurred at one of the restaurants (Table 3).

With respect to menu item sub-categories, an increase of $10 \%$ or more $\mathrm{Na}$ in lunch/dinner entrée offerings was seen at all restaurants. In contrast, findings were more disparate across restaurants for the other sub-categories examined. $\mathrm{Na}$ reductions for side dishes were seen at four of the eight restaurants, with no change $(n 1)$ and an increase ( $n$ 3) observed at the other restaurants. For condiments an increase was observed at five of the seven of the restaurants for which this trend could be examined (nutrition information for condiment offerings was not available from Dairy Queen in the first reporting period, thus percentage change could not be calculated for this restaurant). Decreases in the $\mathrm{Na}$ content of condiments were observed at two of the restaurants.

\section{Discussion}

It has been contended that individual efforts to reduce $\mathrm{Na}$ are mostly ineffective because more than $75 \%$ of dietary $\mathrm{Na}$ comes from prepared foods ${ }^{(9)}$. As a major purveyor of prepared foods, the fast-food industry therefore may contribute to $\mathrm{Na}$ intake of the population; and documenting changes in the Na content of fast-food restaurant menu offerings over time is important to understanding changes in the American food environment.

Results suggest that over the time period studied there has been no meaningful reduction in the Na content of menu offerings at the eight leading fast-food restaurants examined, with the exception of side dishes. Rather, upward trends were evident for the menus as a whole and for entrée and condiment menu offerings. No restaurant examined showed a decrease in $\mathrm{Na}$ in its lunch/dinner menu between 1997/1998 and 2009/2010.

Our findings are somewhat similar to those of the Center for Science in the Public Interest, which has been monitoring the Na content of a limited number of prepared and restaurant foods since 1983. Among the sixty-nine foods tracked by this organization between 1983 and 2004, the average $\mathrm{Na}$ content decreased by 5\% between 1983 and 2004. However, between 1994 and 2004 the average $\mathrm{Na}$ content increased by $6 \%{ }^{(19)}$. Beginning in 2005 the Center for Science in the Public Interest began monitoring a larger sample of food offerings, including an increased assortment of fast-food menu offerings. It measured the change in $\mathrm{Na}$ density ( $\mathrm{Na} \mathrm{mg} / 100 \mathrm{~g}$ product) of each product between 2005 and 2008. Of the eighty-two menu items where $\mathrm{Na}$ density changes could be determined, $50 \%$ showed an increase, $40 \%$ a decrease and 10\% showed no change in Na density ${ }^{(19)}$.

Use of the NCC Food and Nutrition Database for restaurant menu information is both a strength and limitation 
of the present study. Use of this database offers historic information that may not be available directly from restaurant corporations at this time, and has not been archived elsewhere. This database was developed and has been maintained to examine the food and nutrient intake of individuals, and consequently it has some limitations for examining restaurant menu offerings. One shortcoming is that bundled meal offerings (e.g. children's meals, value meals) cannot be examined. For some menu items it is not possible to assess the portions in which they are offered, as they are in the database per piece (e.g. chicken nuggets may be offered as a 4-, 6- or 20-piece order but are included in the database in the unit of 'each'). This shortcoming may result in underestimates of the amount of $\mathrm{Na}$ offered at fast-food chains where many of these types of items are on the menu. This issue should not affect trends because these items were handled in a consistent manner over time in the database. However, this issue precludes us from making valid comparisons of the relative $\mathrm{Na}$ content of menu offerings at each restaurant (e.g. ranking restaurants by the Na content of their menu offerings). Dipping sauces and salad dressings are included in a separate category from the entrée or side dish that they are served with. Hence, this issue must be considered in interpreting $\mathrm{Na}$ trends for entrées and side dishes, as entrée and side salads are typically ordered or eaten with salad dressing. Another shortcoming of the present study is that the chain restaurants included were not selected randomly, which limits the generalizability of study findings. In consideration of this limitation findings from this study are only considered representative of the eight restaurant chains included in the analysis.

Results indicate that consumers wishing to moderate their $\mathrm{Na}$ intake must choose meals very carefully when eating at one of the fast-food restaurants included in the present study. Indeed, choosing a hypothetical idealized meal that contains an entrée, side dish and condiment with the mean Na content for these categories in 2009/2010 would result in a meal that contained $1992 \mathrm{mg} \mathrm{Na}$, which well exceeds the $1500 \mathrm{mg} \mathrm{Na} / \mathrm{d}$ maximum recommended for anyone younger than 14 years, older than 51 years, and those of any age who are African American, or have hypertension, diabetes or chronic kidney disease. Also, this total nears the $2300 \mathrm{mg} \mathrm{Na} / \mathrm{d}$ maximum recommended for everyone else ${ }^{(6)}$.

From a public health perspective, results suggest that stepped-up efforts may be needed to lower the Na content of menu offerings at the leading fast-food restaurants examined in the present study. None of the restaurants examined for the study participates in the National Sodium Reduction Initiative, the public-private partnership created by the New York City Department of Health and Mental Hygiene with support of the Centers for Disease Control and Prevention ${ }^{(25)}$. In July 2011, McDonald's issued a press release pledging to reduce $\mathrm{Na}$ by an average of $15 \%$ overall across its national menu of 
food choices by $2015^{(26)}$, although the present study shows that they had a $55 \%$ increase in $\mathrm{Na}$ in the past 14 years. No other restaurant examined has made any $\mathrm{Na}$ reduction pledge in the USA.

$\mathrm{Na}$ has a complex role in taste, texture and overall flavour of food, as well as having an important role in food preservation and food safety, so it cannot be removed entirely. Salt is an inexpensive, unregulated food additive, and by increasing the amount added a manufacturer can make one brand taste better while simultaneously making a lower-Na competitor's brand taste bland in comparison. Therefore, there are few market forces to support voluntary $\mathrm{Na}$ reduction. Since food needs to be palatably competitive to compete in the consumer marketplace, food producers including fastfood restaurants may be better able to reduce $\mathrm{Na}$ in a regulated and monitored environment. In the 'Strategies to Reduce Sodium Intake' report released by the Institute of Medicine in 2010 it is contended that policy changes, including the US Food and Drug Administration changing salt's status from its current unregulated Generally Recognized as Safe to that of a food additive, are required to create a market environment to support measurable and sustained $\mathrm{Na}$ reduction in the food supply ${ }^{(7)}$. Results from the present study, which indicate that the Na content of menu offerings at eight leading restaurant chains increased between 1997 and 2010, provide some support for this recommendation. Continued and expanded monitoring of the $\mathrm{Na}$ content of restaurant menu offerings, including a representative sample of both fast-food and sit-down restaurants, is warranted to more fully evaluate whether restaurants in the USA are failing to voluntarily lower the $\mathrm{Na}$ content of their menu offerings.

\section{Acknowledgements}

Sources of funding: This study was funded by a grant from the Robert Wood Johnson Foundation Healthy Eating Research program (RWJF 68383). The Robert Wood Johnson Foundation Healthy Eating Research program had no role in the design, analysis or writing of this article. Conflicts of interest: No conflicts of interest exist. Authors' contributions: All authors contributed to the conception and design of the study, interpretation of the data and critical revision of the manuscript. A.R. was responsible for drafting of the manuscript and statistical analysis. L.H. was additionally responsible for acquisition of data, obtaining funding and supervision. All authors read and approved the final manuscript. Acknowledgements: The authors would like to thank Alicia Earnest and Dr Michael Oakes for all of their assistance in data analysis.

\section{References}

1. Danaei G, Ding EL, Mozaffarian D et al. (2009) The preventable causes of death in the United States: comparative risk assessment of dietary, lifestyle, and metabolic risk factors. PLoS Med 6, e1000058.

2. He FJ \& MacGregor GA (2009) A comprehensive review on salt and health and current experience of worldwide salt reduction programmes. J Hum Hypertens $\mathbf{2 3}$, 363-384

3. He FJ \& MacGregor GA (2006) Importance of salt in determining blood pressure in children: meta-analysis of controlled trials. Hypertension 48, 861-869.

4. Cappuccio FP, Kalaitzidis R, Duneclift S et al. (2000) Unravelling the links between calcium excretion, salt intake, hypertension, kidney stones and bone metabolism. J Nephrol 13, 169-177.

5. Tsugane S \& Sasazuki S (2007) Diet and the risk of gastric cancer: review of epidemiological evidence. Gastric Cancer 10, 75-83.

6. US Department of Health and Human Services \& US Department of Agriculture (2010) Dietary Guidelines for Americans, 2010. Washington, DC: US Government Printing Office.

7. Committee on Strategies to Reduce Sodium Intake (2010) Strategies to Reduce Sodium Intake in the United States. Washington, DC: Institute of Medicine.

8. Centers for Disease Control and Prevention (2011) Usual sodium intakes compared with current dietary guidelines United States 2005-2008. MMWR Morb Mortal Wkly Rep 60, 1413-1417.

9. Centers for Disease Control and Prevention (2012) Vital signs: food categories contributing the most to sodium consumption - United States, 2007-2008. MMWR Morb Mortal Wkly Rep 61, 92-98.

10. Powell LM, Chaloupka FJ \& Bao Y (2007) The availability of fast-food and full-service restaurants in the United States: associations with neighborhood characteristics. Am J Prev Med 33, 4 Suppl., S240-S245.

11. Briefel RR \& Johnson CL (2004) Secular trends in dietary intake in the United States. Annu Rev Nutr 24, 401-431.

12. Guthrie JF, Lin BH \& Frazao E (2002) Role of food prepared away from home in the American diet, 1977-78 versus 1994-96: changes and consequences. J Nutr Educ Behav 34, 140-150.

13. Anderson B, Rafferty AP, Lyon-Callo S et al. (2011) Fastfood consumption and obesity among Michigan adults. Prev Chronic Dis 8, A71.

14. Johnson CM, Angell SY, Lederer A et al. (2010) Sodium content of lunchtime fast food purchases at major US chains. Arch Intern Med 170, 732-734.

15. Bauer KW, Larson NI, Nelson MC et al. (2009) Fast food intake among adolescents: secular and longitudinal trends from 1999 to 2004. Prev Med 48, 284-287.

16. US Department of Health and Human Services (1988) The Surgeon General's Report on Nutrition and Health. Washington, DC: US Department of Health and Human Services.

17. American Heart Association (2011) Sodium (Salt or Sodium Chloride). http://www.heart.org/HEARTORG/GettingHealthy/ NutritionCenter/HealthyDietGoals/Sodium-Salt-or-SodiumChloride_UCM_303290_Article.jsp\#food (accessed May 2012).

18. Center for Science in the Public Interest (2005) Salt: The Forgotten Killer. Washington, DC: CSPI.

19. Center for Science in the Public Interest (2008) Salt Assault: Brand Name Comparisons of Processed Foods. Washington, DC: CSPI

20. QSR (2012) Top 50. Quick Service Restaurant Magazine. http://www.qsrmagazine.com/reports/top-50 (accessed May 2012).

21. Westrich B, Buzzard IM, Gatewood L et al. (1994) Accuracy and efficiency of estimating nutrient values in commercial 
food products using mathematical optimization. I Food Compost Anal 77, 223-239.

22. Schakel SF, Buzzard IM \& Gebhardt S (1997) Procedures for estimating nutrient values for food composition databases. I Food Compost Anal 10, 102-114.

23. Schakel SF, Sievert YA \& Buzzard IM (1988) Sources of data for developing and maintaining a nutrient database. $J \mathrm{Am}$ Diet Assoc 88, 1268-1271.

24. Sievert YA, Schakel SF \& Buzzard IM (1989) Maintenance of a nutrient database for clinical trials. Control Clin Trials 10, 416-425.
25. New York City Department of Health and Mental Hygiene (2012) Cutting Salt, Improving Health. http://www.nyc.gov/ $\mathrm{html} / \mathrm{doh} / \mathrm{html} /$ cardio/cardio-salt-initiative.shtml (accessed May 2012)

26. McDonald's (2011) McDonald's ${ }^{\circledR}$ Announces Commitments to Offer Improved Nutrition Choices Long-Term Plan Involves Ongoing Menu Evolution, Nutrition Awareness Communication. http://www.aboutmcdonalds.com/ $\mathrm{mcd} /$ newsroom/electronic_press_kits/mcdonalds_usa_ commitments_to_offer_improved_nutrition_choices/press_ release.html (accessed May 2012). 